Pak. j. sci. ind. res. Ser. B: biol. sci. 2021 64B(3) 274-282

\title{
Effect of Heat Stress for Agro-Economic Traits in Bread Wheat (Triticum Aestivum L.) Genotypes
}

\author{
Wajid Ali Jatoi*a, Abdul Basit Abbasia , Shahnaz Memon ${ }^{c}$, Raza Ali Rind ${ }^{\mathrm{a}}$ \\ and Zulifquar Ali Abbasi ${ }^{b}$ \\ ${ }^{a}$ Department of Plant Breeding and Genetics, Sindh Agriculture University Tandojam, Pakistan \\ ${ }^{\mathrm{b}}$ Department of Agronomy, Sindh Agriculture University Tandojam, Pakistan \\ ${ }^{\mathrm{C}}$ Cotton Section, Agriculture Research Institute, Tandojam, Pakistan
}

(received March 27, 2018; revised March 16, 2019; accepted April 14, 2019)

\begin{abstract}
In the scenario of increasing global warming, heat stress received more importance. Unfortunately, Pakistan is also in the line of most heat affected countries of the world. In this regard, wheat being a most important staple edible crop of Pakistan is highly affected by heat stress. For combating this situation, a study was carried-out on ten bread wheat genotypes viz. Moomal, Mehran, Imdad-05, Anmol91, Benazir, TJ-83, SKD-1, TD-1, Abadgar and Hamal at the Experimental Field, Department of Plant Breeding and Genetics, Sindh Agriculture University, Tandojam. The experiment was laid-out in a randomized complete block design (factorial arrangement) with three replications during Rabi season, 2016-17 in order to assess the response of wheat genotypes to terminal heat stress tolerance. Wheat genotypes were evaluated in two sowing dates viz., on $24^{\text {th }}$ November as a normal planting and late planting on $31^{\text {th }}$ December, 2016 considered as heat stress condition. The analysis of variance revealed significant differences among the genotypes under both sowing dates indicating suitability of the experiment to improve bread wheat genotypes for heat tolerance. Reductions in various traits were observed in late planting which indicated visible effects of heat stress on agro-economic traits. On an average plant height $(\mathrm{cm})$, tillers/plant, spike length $(\mathrm{cm})$, spikelets/spike, grains/spike, 1000-grain weight $(\mathrm{g})$ and grain yield/plant (g) were declined by $-4.63,-2.49,-3.04,-4.35,-16.29,-14.08$ and -9.09 units respectively under the heat stress conditions, while the wheat genotypes like TJ-83, SKD-1 and Mehran showed minimum reductions under heat stress conditions for various traits suggesting their heat tolerance, nonetheless cultivars Moomal and Benazir expressed maximum declines under heat stress expressing their susceptibility to heat stress conditions. The remaining genotypes were found as moderately heat stress tolerant.
\end{abstract}

Keywords: heat stress, yield and its related traits, wheat genotypes

\section{Introduction}

Wheat is one of the most vital species of the Poaceae family grown throughout the world for the persistence of human feeding like bread making and bakery products (Debasis and Khurana, 2001). According to the recent studies, it is reported that $95 \%$ of wheat grown in the world is hexaploid type $(2 n=6 x=42)$. On the basis of production, wheat is placed at second position next to the rice among cereals crops. Wheat is grown in the world on large scale with different environmental conditions. According to the average global grain yield of major cereal crops which was 2520 million tons in 2013-14, to which wheat contributed approximately 715.5 million tons (Singh et al. 2016). It is the cheap source of calories, proteins and carbohydrates in human nutrition. Wheat contributed the major cultivate area in Pakistan, from which $70 \%$ is occupied in Rabi (Farooq

*Author for correspondence; E-mail: jatoiwajid@yahoo.com et al., 2007). In recent past, it was osfinated that the average global temperature will rise about $2{ }^{\circ} \mathrm{C}$ over the next 50 years, and this increase in temperature will make many cereal growing regions less suitable (Wrigley, 2006). Climate change is no longer a majar concern, particularly when it comes to agriculture. Both systems are interconnected and occure on a worldwide scale. The temperature greater than optimal shows adverse effects on plants, is considered as heat stress (Kumar et al., 2015). In cropping system, high temperature is considered as a major problem worldwide with some unexpected spatial and temporal variations, which are responsible for causing reduced plant growth, development and productivity (Parent et al., 2010). It has been assessed that rise of just $1{ }^{\circ} \mathrm{C}$ in temperature during the growing season reduces wheat yields by about 3 to 10\% (Ehsan et al., 2018; Elbasyoni, 2018; You et al., 2009). Wheat is considered as a major staple food crop of Pakistan, where the estimated per capita 
use is about $124 \mathrm{Kg}$ which is highest in the world. In Pakistan, to fulfill the local demand of food, the wheat production should increase by least $4 \%$ to keep up pace with increasing population growth (Khan et al., 2015). Wheat varieties which are commonly grown in Pakistan are very sensitive to heat stress at a stage of grain filling. During this period, heat stress reduces the growth cycle and forces premature ripening of crop, thus shortens the number of grains/spike, declines seed index and ultimately results in deterioration of grain yield and quality of wheat crop (Din et al., 2010).

Wheat is grown in winter season so it is called winter cereal crop and needs nearly low temperature ranging from 12 to $22{ }^{\circ} \mathrm{C}$ considered as optimum temperature for its reproductive phase and development (Farooq et al., 2011). Whereas high temperatures can cause significant morpho-physiological damages which accelerates leaf senescence (Wang et al., 2011), reduces photosynthesis (Ristic et al., 2007), decreases starch biosynthesis (Zhao et al., 2008). Chlorophyll content, canopy temperature depression, biomass, thousand grain weight and grain yield are all effected(Singh et al., 2016). Bala et al. (2014) observed that heat stress significantly reduced grain yield, number of grains per spike, plant height, grain-filling time, peduncle length, peduncle weight and 1000-grain weight. Similarly, according to Rane et al. (2007), the lethal stage of heat stress is responsible for shortening of grain filling period, consequently improper grain filling affects over-all yield of wheat crop. The yield of grain per plant, biological yield per plant and the yield of grain per spike suffered under late sown conditions (Singh et al., 2011). Due to delay in sowing, the total biomass at maturity and yield $/ \mathrm{m}^{2}$ decreases significantly. It is observed that higher temperatures are linked with limitation of water and due to these limitations rapid shrinkage of grain volume can occur (Mitra and Bhatia, 2008). Wheat grain yield is highly affected by biotic and abiotic or environmental stresses (Khavarinejad and Karimov, 2012; Sial et al., 2012; Shamsi et al., 2010). Major biotic stresses include rust (leaf, yellow and stem) and other diseases whereas, environmental constraints which limits crop productivity includes water stress, high temperature and salinity stress (Johari et al., 2011). It is reported that about $20 \%$ of arable land has been affected by drought and soil salinization therefore crop yields have been reduced by $20-30 \%$ throughout the world. The main adverse impacts of climate change on agriculture most probably include temperature variability, different rain fall patterns and increasing rate of evapouration (Elbasyoni, 2018). The environmental changes at global level not only put forward challenges to agriculture sector, but also provide opportunities to boost up crop yields in water stressed environment (Sial et al., 2009; Reynolds et al, 2001). The development of improved germplasm, adapted to the water stress environment, will result in improvement of resources and contribute to sustainable food security. Thus present study is designed to evaluate the popular varieties for their heat tolerance in field condition.

\section{Materials and Methods}

An experiment was conducted at Department of Plant Breeding and Genetics, Sindh Agriculture University, Tandojam. A randomized complete block design with factorial arrangement, where sowing dates were main factor and genotypes were considered as sub-factor. The trial was laid-out in three replications during Rabi season, 2016-17 in order to evaluate the effect of heat stress on agro-economic traits in bread wheat. Two sowing dates were $v i z$., recommended planting $\left(24^{\text {th }}\right.$ November, 2016) and late planting (31 ${ }^{\text {th }}$ December, 2016), under normal and heat stress conditions respectively were used Table 1 . Ten genotypes like Moomal, Mehran, Imadad-05 Anmol-91, Benazir, TJ83, SKD-1, TD-1, Abadgar and Hamal were evaluated for plant height $(\mathrm{cm})$, tillers/plant, spike length $(\mathrm{cm})$, spikelets/spike, grains/spike, 1000-grain weight (g) and grain yield/plant (g). The data was obtained on five randomly tagged index plants from each genotype per replication for the selected traits. The data was statistically analyzed (Statisti 8.1) by using analysis of variance according to Gomez and Gomez (1984). All the inputs like irrigation and fertilizer were given as recommended for the wheat crop.

Table 1. Meteorological data during the experiment 2016-2017

\begin{tabular}{llc}
\hline \hline Month & \multicolumn{2}{c}{ Temperature $\left({ }^{\circ} \mathrm{C}\right)$} \\
\cline { 2 - 3 } & Minimum & Maximum \\
\hline November-2016 & 14.00 & 30.00 \\
December-2016 & 10.20 & 24.20 \\
January-2017 & 7.50 & 24.00 \\
February-2017 & 10.00 & 25.50 \\
March-2017 & 15.50 & 32.00 \\
April-2017 & 22.40 & 40.90 \\
May-2017 & 24.50 & 42.50 \\
\hline \hline
\end{tabular}


The significance of mean squares from analysis of variance (Table 2) revealed that heat stress caused significant impact on plant height, tillers/plant, spike length, spikelets/spike, grains/spike, 1000-grain weight, grain yield/plant. Also significant differences existed among the genotypes for all the agro-economic traits studied that could allow wheat breeders to select the heat tolerant varieties on the basis of morpho-yield characters. The mean squares from analysis of variance for genotype $\mathrm{x}$, the treatment interaction were also significant for all the studied traits. The significance of genotypes $x$ treatment interactions showed that genotypes performed variably over the stress conditions. These interactions could also help wheat breeders to select the best performing varieties based on one or more reliable heat tolerant indicators.

Plant height (cm). The plant height ranged from a minimum of $65.00 \mathrm{~cm}$ (TD-1) to a maximum of 84.60 (Mehran-89cm) under non-stress condition, while in heat stress condition, plant height ranged from minimum of $60.53 \mathrm{~cm}$ (TD-1) to a maximum of $84.40 \mathrm{~cm}$ (Abadgar) (Table 3). The minimum reduction due to heat stress was recorded in TJ-83 $(-3.27 \mathrm{~cm})$ followed by Hamal $(-4.33 \mathrm{~cm})$ and TD-1 $(-4.47 \mathrm{~cm})$, whereas maximum reduction was measured in Moomal (-8.80), although Abagar $(9.20 \mathrm{~cm})$ showed no any reduction in plant height under heat stress condition. The minimum plant height was noticed in TD-1 $(65.00 \mathrm{~cm})$ followed by SKD-1 $(72.20 \mathrm{~cm})$ and Benazir $(72.27 \mathrm{~cm})$, whereas maximum plant height was recorded in Mehran (84.60 $\mathrm{cm})$ under non-stress conditions. The minimum plant height was recorded in TD-1 $(60.53 \mathrm{~cm})$ followed by SKD-1 $(65.00 \mathrm{~cm})$ and Benazir $(66.00 \mathrm{~cm})$ whereas the maximum plant height was recorded in Abadgar (84.40 $\mathrm{cm})$ under heat stress condition.
Tillers/plant. Maximum range of tillers/plant of 11.00 were observed in genotype TD-1 and minimum was recorded in Benazir and SKD-1 (8.73) under non-stress condition, while the maximum tillers/plant ranged from 8.33 (TD-1) to a minimum in Benazir and Hamal each (6.07) in heat stress conditions (Table 3). The minimum relative decrease was noted in SKD-1 (-1.33) closely followed by Anmol-91 (-1.87) and TJ-83 (-1.93) and maximum decrease was noted in Hamal (-3.47) under heat stress conditions. The maximum tillers/plant were counted in TD-1 (11.00) closely followed by Mehran (9.73) and Hamal (9.53) and minimum in Benazir and SKD-1 (8.73) under non-stress conditions. Whereas in heat stress condition maximum tillers/plant were noted in TD-1 (8.33) closely followed by SKD1 (7.40) and Anmol-91 (7.20) and minimum were found in Benazir and Hamal (6.07).

Spike length $(\mathbf{c m})$. In non-stress, the range of spike length $(\mathrm{cm})$ was measured maximum in TD-1 $(13.67 \mathrm{~cm})$ and minimum in Anmol-91 $(10.00 \mathrm{~cm})$, while in heat stress condition, maximum spike length $(\mathrm{cm})$ was recorded in TJ-83 $(12.93 \mathrm{~cm})$ and minimum in Anmol$91(7.33 \mathrm{~cm})$ (Table 4). The minimum relative decrease in spike length $(\mathrm{cm})$ was observed in TJ-83 $(-0.53 \mathrm{~cm})$ followed by Benazir (-2.47), Anmol-91, SKD-1 and Hamal $(2.67 \mathrm{~cm}$ each) and maximum reduction was recorded in Imdad-05 $(-5.07 \mathrm{~cm})$ under heat stress condition. The maximum spike length $(13.67 \mathrm{~cm})$ was recorded in TD-1 and closely followed by TJ-83 and Benazir ( 13.47 and $13.33 \mathrm{~cm}$ ) respectively, whereas the minimum spike length $(10.00 \mathrm{~cm})$ was noted in Anmol91 under non-stress condition. The maximum spike length was recorded in TJ-83 $(12.93 \mathrm{~cm})$ followed by Benazir and TD-1 (10.87 and $10.27 \mathrm{~cm})$ respectively

Table 2. Mean squares from analysis of variances of wheat genotypes for various traits grown under non stress and heat stress conditions

\begin{tabular}{llllll}
\hline \hline Characters & \multicolumn{5}{c}{ Mean squares } \\
\cline { 2 - 6 } & $\begin{array}{l}\text { Replication } \\
(\text { D.F. }=2)\end{array}$ & $\begin{array}{l}\text { Genotypes } \\
(\text { D.F. }=9)\end{array}$ & $\begin{array}{l}\text { Treatments } \\
(\text { D.F. }=1)\end{array}$ & $\begin{array}{l}\text { G x T } \\
\text { (D.F. }=9)\end{array}$ & $\begin{array}{l}\text { Error } \\
\text { (D.F. }=38)\end{array}$ \\
\hline Plant height & 9.99 & $185.94^{* *}$ & $322.01^{* *}$ & $40.27^{* *}$ & 6.22 \\
Tillers/plant & 0.86 & $2.34^{* *}$ & $93.25^{* *}$ & $0.62^{* *}$ & 0.36 \\
Spike length & 1.09 & $9.11^{* *}$ & $138.62^{* *}$ & $2.20^{* *}$ & 0.39 \\
Spikelets/spike & 5.32 & $22.74^{* *}$ & $283.40^{* *}$ & $5.92^{* *}$ & 1.29 \\
Grains/spike & 2.22 & $255.96^{* *}$ & $3978.83^{* *}$ & $25.49^{* *}$ & 3.47 \\
1000-grain weight & 0.82 & $85.05^{* *}$ & $2973.70^{* *}$ & $27.59^{* *}$ & 0.77 \\
Grain/yield plant & 1.97 & $10.30^{* *}$ & $1239.15^{* *}$ & $7.04^{* *}$ & 1.10 \\
\hline \hline
\end{tabular}

** = Significant at $1 \%$ probability level 
and minimum spike length was recorded in Anmol-91 $(7.33 \mathrm{~cm})$ under heat stress condition

Spikelets/spike. In non-stress, the maximum range of spikelets/spike was counted in Benazir (23.67) and the minimum in Hamal (16.33). In heat stress, maximum spikelets/spike were counted in TJ-83 and TD-1 (18.00 each) and the minimum were recorded in Abadgar (12.33). The minimum relative decrease in spikelets/ spike was observed in SKD-1(-1.80) followed by Hamal and TJ-83 (-2.67 and -3.07$)$ respectively where maximum reduction was recorded in Abadgar (-8.13) under heat stress over non stress condition (Table 4). The maximum spikelets/spike were noted in Benazir (23.67) narrowly followed by TD-1 (23.00), whereas the minimum spikelets/spike were calculated in Hamal (16.33) under non stress condition. The maximum spikelets/spike were recorded in TJ-83 and TD-1 (18.00) followed by Moomal and SKD-1 (17.53 and 17.27 respectively) whereas the minimum spikelets/spike were recorded by Abadgar (12.33) under heat stress condition.

Table 3. Mean performance for plant height $(\mathrm{cm})$ and tillers/plant of wheat genotypes grown under non stress and heat stress condition

\begin{tabular}{|c|c|c|c|c|c|c|}
\hline \multirow[t]{2}{*}{ Genotypes } & \multicolumn{2}{|c|}{ Plant height $(\mathrm{cm})$} & \multirow[t]{2}{*}{ R.D.* } & \multicolumn{2}{|l|}{ Tillers/plant } & \multirow[t]{2}{*}{ R.D.* } \\
\hline & Non-stress & Heat stress & & Non-stress & Heat stress & \\
\hline Moomal & 78.80 & 70.00 & -8.80 & 9.20 & 6.67 & -2.53 \\
\hline Mehran & 84.60 & 76.00 & -8.60 & 9.73 & 6.40 & -3.33 \\
\hline Imadad-05 & 77.40 & 70.67 & -6.73 & 8.80 & 6.27 & -2.53 \\
\hline Anmol-91 & 73.53 & 67.67 & -5.87 & 9.07 & 7.20 & -1.87 \\
\hline Benazir & 72.27 & 66.00 & -6.27 & 8.73 & 6.07 & -2.67 \\
\hline TJ-83 & 74.87 & 71.60 & -3.27 & 8.87 & 6.93 & -1.93 \\
\hline SKD-1 & 72.20 & 65.00 & -7.20 & 8.73 & 7.40 & -1.33 \\
\hline TD-1 & 65.00 & 60.53 & -4.47 & 11.00 & 8.33 & -2.67 \\
\hline Abadgar & 75.20 & 84.40 & -9.20 & 9.00 & 6.40 & -2.60 \\
\hline Hamal & 80.80 & 76.47 & -4.33 & 9.53 & 6.07 & -3.47 \\
\hline Mean & 75.47 & 70.83 & -4.63 & 9.26 & 6.77 & -2.49 \\
\hline$\overline{\mathrm{LSD}}$ at $5 \%(\mathrm{G})$ & 2.91 & & & 0.70 & & \\
\hline LSD at $5 \%(T)$ & 1.30 & & & 0.31 & & \\
\hline LSD at $5 \%(\mathrm{G} \times \mathrm{T})$ & 4.12 & & & 0.99 & & \\
\hline
\end{tabular}

R.D* = Relative decrease under heat stress over the non-stress

Table 4. Mean performance for spike length and spikelets/spike of wheat genotypes grown under non stress and heat stress condition

\begin{tabular}{|c|c|c|c|c|c|c|}
\hline \multirow[t]{2}{*}{ Genotypes } & \multicolumn{2}{|c|}{ Spike length $(\mathrm{cm})$} & \multirow[t]{2}{*}{ R.D.* } & \multicolumn{2}{|c|}{ Spikelets/spike } & \multirow[t]{2}{*}{ R.D.* } \\
\hline & Non-stress & Heat stress & & Non-stress & Heat stress & \\
\hline Moomal & 12.13 & 9.00 & -3.13 & 21.33 & 17.53 & -3.80 \\
\hline Mehran & 12.07 & 8.67 & -3.40 & 20.33 & 16.93 & -3.40 \\
\hline Imadad-05 & 12.73 & 7.67 & -5.07 & 20.67 & 15.47 & -5.20 \\
\hline Anmol-91 & 10.00 & 7.33 & -2.67 & 17.07 & 13.67 & -3.40 \\
\hline Benazir & 13.33 & 10.87 & -2.47 & 23.67 & 16.67 & -7.00 \\
\hline TJ-83 & 13.47 & 12.93 & -0.53 & 21.07 & 18.00 & -3.07 \\
\hline SKD-1 & 12.33 & 9.67 & -2.67 & 19.07 & 17.27 & -1.80 \\
\hline TD-1 & 13.67 & 10.27 & -3.40 & 23.00 & 18.00 & -5.00 \\
\hline Abadgar & 13.07 & 8.67 & -4.40 & 20.47 & 12.33 & -8.13 \\
\hline Hamal & 12.33 & 9.67 & -2.67 & 16.33 & 13.67 & -2.67 \\
\hline Mean & 12.51 & 9.48 & -3.04 & 20.30 & 15.95 & -4.35 \\
\hline$\overline{\mathrm{LSD}}$ at $5 \%(\mathrm{G})$ & \multicolumn{2}{|c|}{0.73} & \multicolumn{4}{|c|}{1.32} \\
\hline LSD at $5 \%(\mathrm{~T})$ & \multirow{2}{*}{\multicolumn{2}{|c|}{$\begin{array}{l}0.32 \\
1.03\end{array}$}} & \multicolumn{4}{|c|}{0.59} \\
\hline LSD at $5 \%(\mathrm{G} \times \mathrm{T})$ & & & \multicolumn{4}{|c|}{1.87} \\
\hline
\end{tabular}

R.D* = Relative decrease under heat stress over the non-stress 
Grains/spike. In non stress (Table 5) the maximum range of grains/spike were counted in TD-1 (70.00) and minimum were counted in Anmol (49.20). While in heat stress the maximum grains/spike were counted in TJ-83 (53.33) and minimum were counted in Anmol91 (31.73). The minimum relative decrease in grains/spike was shown by Mehran (-7.07) closely followed Imdad-05 and TJ-83 (-12.40 and -15.33) respectively. The maximum grains/spike were obtained by TD-1 (70.00) followed TJ-83 and Moomal (68.67 and 67.53) respectively whereas the minimum grains/ spike were acquired by Anmol-91 (49.20) in non-stress condition, while in heat stress condition the maximum grains/spike were obtained by TJ-83 (53.33) followed by Moomal and Mehran (51.00 and 48.00) respectively and the minimum grains/spike were obtained from Anmol-91 (31.73) in heat stress condition.

1000 grain weight (g). In non-stress, the maximum range in 1000 grain weight (Table 5) was weighed in TD-1 (53.43 g) and minimum was counted in Anmol$91(39.80 \mathrm{~g})$. While in heat stress condition the maximum range of 1000 grain weight was observed in Mehran$89(40.00 \mathrm{~g})$ and the minimum was counted in Abadgar $(26.03 \mathrm{~g})$. The lowest relative decrease percentage however was recorded by Mehran (-6.17 g) followed by TJ-83 (-9.83 g) and Hamal (-10.33 g). The maximum relative decrease was showed by Benazir (-17.97) under heat stress condition. The highest 1000 grain weight (g) exhibited by genotype TD-1 (53.43 g) followed by Moomal and Benazir (50.57 and $48.47 \mathrm{~g}$ ) respectively and minimum by Anmol-91 (39.80 g) in non-stress condition, while in heat stress condition, the higher 1000 grain weight (g) was obtained from Mehran (40.00) closely followed by TJ-83, Moomal and TD-1 (38.33, 36.00 and $36.00 \mathrm{~g}$ ) respectively and the minimum 1000 grain weight ( $\mathrm{g}$ ) was acquired by Abadgar (26.03) in heat stress condition.

Grain yield/plant (g). The higher grain yield/plant is the ultimate goal of all the plant breeders. The increment of all other characters provides a better background to increase the grain yield/plant. In our experiment maximum grain yield/plant was ranged from $21.03 \mathrm{~g}$ (Moomal) to minimum $16.40 \mathrm{~g}$ (Abadgar) in non-stress condition (Table 6), while in heat stress condition, maximum range of $11.33 \mathrm{~g}$ was recorded from TD-1 and minimum of $6.10 \mathrm{~g}$ from SKD-1. The greatest performance was observed in TJ-83 with minimum reduction of $-5.90 \mathrm{~g}$ followed by Hamal and Abadgar $(-7.1$ and $-7.40 \mathrm{~g})$ respectively under heat stress condition. The maximum relative decrease percentage was shown by Moomal (-11.70 g) in terminal heat stress condition. The maximum grain yield/plant was obtained by Moomal (21.03 g) followed by Benazir and TD-1 (20.53 and $20.23 \mathrm{~g}$ ) respectively and the minimum by Abadgar (16.40 g) in non-stress condition, while in heat stress condition the maximum grain yield/plant was shown by TD-1 (11.33 g) closely followed by TJ-83 (11.00) and the minimum grain yield/plant was obtained from SKD-1 (6.10 g).

Table 5. Mean performance for grains/spike and 1000 grain weight of wheat genotypes grown under non stress and heat stress condition

\begin{tabular}{|c|c|c|c|c|c|c|}
\hline \multirow[t]{2}{*}{ Genotypes } & \multicolumn{2}{|c|}{ Grains/spike } & \multirow[t]{2}{*}{ R.D.* } & \multicolumn{2}{|c|}{1000 grain weight $(\mathrm{g})$} & \multirow[t]{2}{*}{ R.D.* } \\
\hline & Non-stress & Heat stress & & Non-stress & Heat stress & \\
\hline Moomal & 67.53 & 51.00 & -16.53 & 50.57 & 36.00 & -14.57 \\
\hline Mehran & 55.07 & 48.00 & -7.07 & 46.17 & 40.00 & -6.17 \\
\hline Imadad-05 & 54.40 & 42.00 & -12.40 & 47.50 & 30.37 & -17.13 \\
\hline Anmol-91 & 49.20 & 31.73 & -17.47 & 39.80 & 27.67 & -12.13 \\
\hline Benazir & 65.00 & 45.67 & -19.33 & 48.47 & 30.50 & -17.97 \\
\hline TJ-83 & 68.67 & 53.33 & -15.33 & 48.17 & 38.33 & -9.83 \\
\hline SKD-1 & 57.13 & 40.00 & -17.13 & 44.70 & 28.83 & -15.87 \\
\hline TD-1 & 70.00 & 47.67 & -22.33 & 53.43 & 36.00 & -17.43 \\
\hline Abadgar & 54.93 & 37.67 & -17.27 & 45.40 & 26.03 & -19.37 \\
\hline Hamal & 62.00 & 44.00 & -18.00 & 42.67 & 32.33 & -10.33 \\
\hline Mean & 60.39 & 44.11 & -16.29 & 49.69 & 32.61 & -14.08 \\
\hline LSD at $5 \%(\mathrm{G})$ & \multicolumn{2}{|c|}{2.17} & \multicolumn{4}{|c|}{1.02} \\
\hline LSD at $5 \%(\mathrm{~T})$ & \multicolumn{2}{|c|}{0.97} & \multicolumn{4}{|c|}{0.45} \\
\hline LSD at $5 \%(\mathrm{G} \times \mathrm{T})$ & \multicolumn{2}{|c|}{3.07} & \multicolumn{4}{|c|}{1.45} \\
\hline
\end{tabular}

R.D* = Relative decrease under heat stress over the non-stress 
Table 6. Mean performance for grain yield/plant of wheat genotypes grown under non stress and heat stress condition

\begin{tabular}{|c|c|c|c|}
\hline \multirow[t]{2}{*}{ Genotypes } & \multicolumn{2}{|c|}{ Grain yield/plant } & \multirow[t]{2}{*}{ R.D.* } \\
\hline & Non-stress & Heat stress & \\
\hline Moomal & 21.03 & 9.33 & -11.70 \\
\hline Mehran & 16.43 & 9.00 & -7.43 \\
\hline Imadad-05 & 19.33 & 8.22 & -11.11 \\
\hline Anmol-91 & 16.60 & 8.20 & -8.40 \\
\hline Benazir & 20.53 & 9.26 & -11.28 \\
\hline TJ-83 & 16.90 & 11.00 & -5.90 \\
\hline SKD-1 & 17.73 & 6.10 & -11.63 \\
\hline TD-1 & 20.23 & 11.33 & -8.90 \\
\hline Abadgar & 16.40 & 9.00 & -7.40 \\
\hline Hamal & 16.47 & 9.33 & -7.13 \\
\hline Mean & 18.17 & 9.08 & -9.09 \\
\hline$\overline{\mathrm{LSD}}$ at $5 \%(\mathrm{G})$ & \multicolumn{2}{|c|}{1.22} & \\
\hline LSD at $5 \%(\mathrm{~T})$ & \multicolumn{2}{|c|}{0.54} & \\
\hline LSD at $5 \%(\mathrm{G} \times \mathrm{T})$ & \multicolumn{2}{|c|}{1.73} & \\
\hline
\end{tabular}

R.D* $=$ Relative decrease under heat stress over the non-stress

\section{Results and Discussion}

Global warming is the burning issue of present day world. In the scenario of increasing population of human and decreasing trend of green land portion, it is observed that heat stress will be increasing in coming years. Due to increasing world population, the necessities of food will also be increased. On one side, the world population is continuously increasing and on the other side cultivable land is decreasing, so it will be a massive issue in future, for human food. That's why there is dire need of research on wheat crop to develop heat tolerant varieties or the varieties which mature earlier, thus escape the terminal heat stress. The effect of different sowing dates related to high temperatures on ten bread wheat genotypes were studied and the observations were recorded on various yield and yield contributing traits. The results described in previous chapter are discussed as under.

The mean squares from analysis of variance (Table 2) indicated that heat stress imposed significant impact on plant height, tillers/plant, spike length, spikelets/spike, grains/spike, 1000-grain weight and grain yield/plant. There also existed significant differences among the genotypes for all the yield and its associated traits studied that could allow wheat breeders to select the heat tolerant genotypes for one or more morph-yield attributes. Genotype $\times$ treatment interactions was also significant for all the traits. The significance of genotype $x$ treatment interaction showed that genotypes performed differently over the stress condition. These interactions also could help wheat breeders to select the best performing varieties based on one or more reliable heat tolerant indicators. Similarly Abd-El-Rahman et al. (2014) evaluated 12 bread wheat genotypes at two sowing dates (November 15 and December 15) in order to make the normal and heat stress conditions. The results showed notable changes in genotypes for the influence of sowing date on the studied characters, except for days to $50 \%$ heading, spikelets/spike, grains/spike and grains/plant. Furthermore, genotypes $\times$ sowing date interaction $(\mathrm{G} \times \mathrm{S})$ expressed notable changes for plant height and 1000-kernel weight. For the other characters, $\mathrm{G} \times \mathrm{S}$ expressed no significant changes under the normal temperature, whereas the yield ranged remained 1.55 to 2.80 ton/ha.

The minimum decline was observed in genotypes such as TJ-83,Hamal and TD-1 for plant height, tillers/plant, spike length and spikelets/spike, whereas the maximum reduction was recorded in genotypes Abadgar, SKD-1, Anmol-91 and TJ-83 under the heat stress in late sowing condition for above the traits. Terminal heat stress reduced the number of grains per spike to a significant extent in wheat. The lowest reduction was observed in Mehran followed by Imdad- 05 and TJ-83 under the heat stress condition. Our results are in agreement with El-Nakhlawy et al. (2015) who showed that sowing date of $16^{\text {th }}$ December averagely increased the plant height, productive tillers/plant, spike length, spikelets/ spike, grain weight/plant, 100-grain weight, grain yield/ ha by $20,17,33,75,85,7,21$ and $10 \%$ respectively, over rest of the sowing dates. While genotypes showed significant changes to these characters from level of increments, viz., 29, 59, 164, 166, 179, 111, 203 and $46 \%$ by varieties $\mathrm{F}-10$ and $\mathrm{F}-50$ for all the evaluated characters respectively. The best combination was phenotypically observed in terms of heat tolerance under arid conditions shown by interaction of F-10 and F-50 in December plantation. Abd-El-Rahman et al. (2014) evaluated 12 bread wheat genotypes at two sowing dates (November $15^{\text {th }}$ and December $15^{\text {th }}$ ) in order to observe heat effects on different morphological traits. They found notable changes in genotypes on the studied characters, except for spikelets/spike, grains/spike and grains/plant. They also found that under normal temperature, the yield ranged between 1.55 to 2.80 ton/ha. Whereas, at heat stress condition, the yield range stood between 1.20-2.42 ton/ha and observed that up to $16 \%$ yield losses occurred by heat stress. The findings of positive direct effect between spikelets number per 
spike with yield determined in the study is in agreement with the studies of (El-Ameen, 2012; Mahmood et al., 2006; Abd El-Majeed, 2005; Sial et al., 2005; Gupta et al., 2004) they also reported that heat stress caused a significant reduction in the number of grains per spike under high temperature conditions. These finding are also supported by Hamam et al. (2015), they found a decline of $18.13 \%$ in grains numbers per spike due to heat stress

Seed index is one of the most important yield contributing traits while terminal heat stress is the major environmental factor which reduces the size and boldness of grain. Menshawy (2007) reported higher reductions in kernel weight under the late planting which could be accounted by the reduction in grain filling period. In our case, the minimum reduction was recorded in Mehran followed by TJ-83 and Hamal, whereas the maximum reduction was found in Abadgar in heat stress conditions. This reduction may be attributable to high temperatures affecting the grain maturity which resulted in shrunk kernels. Increasing grain yield per plant and yield contributing traits is the ultimate goal of wheat breeders. According to Hays et al. (2007) stress occurring after anthesis often cause detrimental effects on wheat grain yield by hastening maturity, triggering pre-mature senescence, shortening grain filling duration and reducing net assimilates and 1000-grain weight. In current study, the best performance was shown by the genotype TJ-83 with minimum decrease followed by genotypes Hamal and Abadgar. In normal condition, the grain yield per plant maximum ranged was obtained from genotype Moomal and minimum in Abadgar, whereas under heat stress condition, maximum grain yield per plant was recorded by the genotype TD-1 and by SKD-1. Abdullah et al. (2007) reported that traits such as 1000-grain weight, test weight and flour yield declined progressively with delayed sowing. El-Ameen (2012) reported that delay in the sowing resulted in a substantial reduction in grain yield by $63.34 \%$, while the genotypes under favorable conditions performed well for grain yield. Our results are in agreement with those of (Hossain et al., 2015; Abd-El-Rahman et al., 2014: Alam et al., 2014; Mondal et al., 2013) they also reported that heat stress reduced grain yield up to 40 , 45 and $49.5 \%$, respectively and sigh et al. (2016) Hamam et al. (2015), Hossain et al. (2015) reported that terminal heat stress reduced the seed index similar to our results. Furthermore Bala and Sikder (2018a and 2018b) they reported that at heat stress condition values of all the parameters such as plant height and grain yields were reduced compared to normal condition. Elbasyoni (2018) who observed that cultivar "Sids12" was stable and outperformed other tested cultivars under combined sowing dates across environments. However, cultivar "Gemmeiza9" was more stable and outperformed other cultivars across environments under the recommended sowing date. Moreover, cultivar "Gemmeiza12" was the ideal cultivar for the late sown condition.

\section{Conclusion}

The analysis of variance revealed significant differences among all the genotypes under normal and high temperatures indicating the suitability of experiment to improve bread wheat genotypes for heat tolerance. The varieties SKD-1, TJ-83 and Mehran showed minimum reductions for various traits under heat stress conditions, thus showing their tolerance to heat stress while TD-1 and TJ-83 expressed maximum declines under terminal heat stress conditions for all the studied traits, showing their susceptibility to heat stress. In non-stress as well as under heat stress conditions, the highest values were recorded by the genotypes TD-1, Moomal and Benazir.

Conflict of Interest. The authors declare no conflict of interest.

\section{References}

Abd El-Majeed, S.A., Mousa, A.M., Abd El-Kareem, A.A. 2005. Effect of heat stress on some agronomic traits of bread wheat (Triticum aestivum L.) genotypes under upper Egypt conditions. Fayoum Journal of Agriculture Research and Development, 19: 4-16.

Abd-Elrahman, N.M., Ali, A.B., Alhadi, M., ShuangEn, Y. 2014. A field screening of twelve wheat genotypes under late sowing conditions. AmericanEurasian Journal of Agriculture and Environmental Sciences, 14: 978-984.

Abdullah, M., Rehman, A., Ahmad, N., Rasul, I. 2007. Planting time effect on grain and quality characteristics of wheat. Pakistan Journal of Agriculture Sciences, 44: 200-202.

Alam, M.N., Bodruzzaman, M., Hossain, M.M., Sadekuzzaman, M. 2014. Growth performance of spring wheat under heat stress condition. International Journal of Agronomy and Agriculture Research, 4: 91-103.

Bala, P., Sikder, S. 2018a. Wheat genotypes as affected 
by terminal heat stress in northern Bangladesh. Bangladesh Agronomy Journal, 21: 25-37.

Bala, P., Sikder, S. 2018b. Effect of heat stress on physiological traits in wheat genotype. The Journal of Agriculture Sciences, 13: 31-44.

Bala, S., Asthir, B., Bains, N.S. 2014. Effect of terminal heat stress on yield and yield attributes of wheat. Indian Journal of Applied Research, 4: 1-2.

Debasis, P., Khurana, P. 2001. Wheat biotechnology: A mini review. Electronic Journal of Biotechnology, 4: $1-25$.

Din, R., Subhani, G., Ahmad, N., Hussain, M., Rhman, A. 2010. Effect of temperature on development and grain formation in spring wheat. Pakistan Journal of Botany, 42: 899-906.

El-Ameen, T. 2012. Stability analysis of selected wheat genotypes under different environment conditions in Upper Egypt. African Journal of Agriculture Research, 34: 4838-4844.

Elbasyoni, I.S. 2018. Performance and stability of commercial wheat cultivars under terminal heat stress. Agronomy, 8: 2-20.

Ehsan, E., Rezaeia, Siebert, S., Manderscheid, S., Müller, J., Mahrookashania,A., Ehrenpfordt, S., Haenschd, J. 2018. Quantifying the response of wheat yields to heat stress. Field Crops Research Journal, 5: 11-52.

El-Nakhlawy, F., Alghabari, F., Ihsan, M.Z. 2015. Response of wheat genotypes to planting dates in the arid region. Scientia Agriculturae, 10: 59-63.

Farooq, M., Bramley, H., Palta, J.A., Siddique, K.H.M. 2011. Heat stress in wheat during reproductive and grain filling-phases. Critical Review of Plant Science, 30: 491-507.

Farooq, A.M., Yaqoob, I.,Sadozai, K.N. 2007. Varietal adoption effect on wheat crop production in irrigated areas of NWFP. Sarhad Journal of Agriculture, 23: 807-814.

Gomez, K.A., Gomez, A.A. 1984. Statistical Procedures for Agricultural Research. $2^{\text {nd }}$ (ed.) John Wiley \& Sons Inc., New York, U.S.A.

Gupta, R.S., Singh, R.P., Tiwari, D.K. 2004. Analysis of path coefficient for yield and its related characters in bread wheat (Triticum aestivum L. Em Thell). Advances in Plant Sciences, 17:299-302.

Hamam, K.A., Khaled, A.G.A., Zakaria, M.M. 2015. Genetic stability and diversity in yield components of some wheat genotypes through seasons and heat stress under different locations. Journal of Plant Production Mansoura University, 6: 349 -370.
Hays, D.B., Do, J.H., Mason, R.E., Morgan, G., Finlayson, S.A. 2007. Heat stress induced ethylene production in developing wheat grains induced kernel abortion and increased maturation in susceptible cultivars. Plant Sciences, 172: 1113-1123.

Hossain, M.I., Hakim, M.A., Mondal, M.R.I., Gathala M., Barma, N.C.D. 2015. Phenological variation and its relation with yield in several wheat genotypes under normal and late sowing heat stress conditions in Bangladesh. Journal of Dynamic Agriculture Research, 2: 1-11.

Johari, M.P., Habib, M. 2011. Evaluation of 10 wheat cultivars under water stress at Moghan (Iran) condition. African Journal of Biotechnology, 10: 10900-10905.

Khan, S.U., Din, J.U., Qayyum, A., Jan N.E., Jenks, M.A. 2015. Heat tolerance indicators in Pakistani wheat (Triticum aestivum L.) genotypes. Acta Botanica Croatica, 74: 109-121.

Kumar, A., Sengar, R.S., Singh, R., Rani, A., Shukla, G., Girdharwal, V. 2015. Screening of heat tolerance wheat germplasm under late seeded condition. Journal of Environment and Applied Bioresearch, 3: 206-210.

Khavarinejed, M.S., Karmov, M. 2012. Study of genetic diversity among spring wheat genotypes in drought stress by advanced statistical analysis. Internal Journal Agronomy and Plant Production, 3: 590598.

Mahmood, Q., Lei, W.D., Qureshi, A.S., Khan, M.R., Hayat, Y., Jilani, G., Shamsi, I.H., Tajammal, M.A., Khan, M.D. 2006. Heterosis, correlation and path analysis of morphological and biochemical characters in wheat (Triticum aestivum $\mathrm{L}$. Emp.Thell). Agricultural Sciences, 1: 180-185.

Mitra, R., Bhatia, C.R. 2008. Bioenergetics cost of heat tolerance in wheat crop. Current Science, 94: 10491053.

Menshawy, A.M.M. 2007. Evaluation of some early bread wheat genotypes under different sowing dates: 1. Earliness characters. Egyptian Journal of Plant Breeding, 11: 25-40.

Mondal, S., Singh, R.P., Crossa, J., Espino, J.H., Sharma, I. 2013. Earliness in wheat: A key to adaptation under terminal and continual high temperature stress in South Asia. Field Crops Research, 151: 19-26.

Parent, B., Turc, O., Gibon, Y., Stitt, M.,Tardieu,F. 2010. Modeling temperature-compensated physiological rates, based on the coordination of responses to 
temperature of developmental processes. Journal of Experimental Botany, 61: 2057-2069.

Rane, J., Pannu, R.K., Sohu, V.S., Saini, R.S., Mishra, B., Shoran, J., Crossa, J., Vargas, M., Joshi, A.K. 2007. Performance of yield and stability of advanced wheat genotypes under heat stressed environments of Indo-Gangetic Plains. Crop Science, 47: 15611573

Ristic, Z., Bukovnik, U., Parsad, P.V.V. 2007. Correlation between heat stability of thylakoid membranes and loss of chlorophyll in winter wheat under heat stress. Crop Science, 47: 2060-2073.

Reynold, M.P., Nagavajan, S., Razzaque, M.A., Ageeb, O.A.A. 2001. Heat tolerance. in: Application of physiology in wheat breeding (Eds): Reynold, M.P., J.I. Ortiz-Monasterio and A.Mc. Nab. Mexico, D.F. CIMMYT, 124-135.

Shamsi, K.M., Petrosyan, G., Noor- Mohammadi, Haghparast, R. 2010. The role of water deficit stress and water use efficiency on bread wheat cultivars. Journal of Applied Biological Sciences, 35: 23312335.

Sial, M.A.,.Arain, M.A., Khanzada, S., Naqvi, M.H., Dahot, M.U., Nizamani N.A. 2005. Yield and quality parameters of wheat genotypes as affected by sowing dates and high temperature stress. Pakistan Journal of Botany, 37: 575-58.

Sial, M.A., Laghari, K.A., Panhwar, N.A., Arian, M.A Baloch, G.M. 2012. Genetic improvement of drought tolerance in semi-dwarf wheat. Science
Technology and Development, 31: 335-340.

Sial, M.A., Dahot, M.U., Arain, M.A., Markhand, G.S, Mangrio, S.M., Naqvi, M.H., Laghari, K.A., Mirbahar, A.A. 2009. Effect of water stress on yield components of semi dwarf Bread wheat (Triticum aestivum L). Pakistan Journal of Botany, 41: 1715 1728.

Singh, K., Sharma, S.N., Sharma, Y. 2011. Effect of high temperature on yield attributing traits in bread wheat. Bangladesh Journal of Agriculture Research, 36: 415-426.

Singh, R., Khajuria, P., Singh, A.K. 2016. Effect of heat stress on grain weight in bread weight. Indian Journal of Applied Research, 6: 323-327.

Wang, X., Cai, J., Jiang, D., Liu, F., Dai, T., Cao, W. 2011. Pre-anthesis high-temperature acclimation alleviates damage to the flag leaf caused by postanthesis heat in wheat. Journal of Plant Physiology, 168: $585-593$.

Wrigley, C. 2006. Global warming and wheat quality. Cereal Foods World, 51: 34-36.

You, L., Rosegrant, M.W., Wood, S., Sun, D. 2009. Impact of growing season temperature on wheat productivity in China. Agriculture Forestry and Meteorology, 149: 1009-1014.

Zhao, H., Dai, T., Jiang, D., Cao, W. 2008. Effects of high temperature on key enzymes involved in starch and protein formation in grains of two wheat cultivars. Journal of Agronomy and. Crop Sciences, 194: $149-158$ 